\title{
Danegaptide for primary percutaneous coronary intervention in acute myocardial infarction patients: a phase 2 randomised clinical trial
}

\author{
Thomas Engstrøm, ${ }^{1,2}$ Lars Nepper-Christensen, ${ }^{1}$ Steffen Helqvist, ${ }^{1}$ Lene Kløvgaard, ${ }^{1}$ \\ Lene Holmvang, ${ }^{1}$ Erik Jørgensen, ${ }^{1}$ Frants Pedersen, ${ }^{1}$ Kari Saunamaki, ${ }^{1}$ \\ Hans-Henrik Tilsted, ${ }^{1}$ Adam Steensberg, ${ }^{3}$ Søren Fabricius, ${ }^{3}$ Ulrik Mouritzen, ${ }^{3}$ \\ Niels Vejlstrup, ${ }^{1}$ Kiril A Ahtarovski, ${ }^{1}$ Christoffer Göransson, , Litten Bertelsen, \\ Kasper Kyhl, ${ }^{1}$ Göran Olivecrona, ${ }^{2}$ Henning Kelbæk, ${ }^{4}$ Jens Flensted Lassen, ${ }^{1}$ Lars Køber, ${ }^{1}$ \\ Jacob Lønborg ${ }^{1}$
}

- Additional material is

published online only. To view please visit the journal online (http://dx.doi.org/10.1136/ heartjn-2017-312774).

'Department of Cardiology, Rigshospitalet, University of Copenhagen, Copenhagen, Denmark

${ }^{2}$ Department of Cardiology, University of Lund, Lund, Sweden

${ }^{3}$ Zealand Pharma A/S Copenhagen, Denmark ${ }^{4}$ Department of Cardiology, Zealand University Hospital, Roskilde, Denmark

Correspondence to Professor Thomas Engstrom, Department of Cardiology, Rigshospitalet, University of Copenhagen, Copenhagen 2100, Denmark ; thomas. engstroem@regionh.dk

Received 27 November 2017 Revised 28 February 2018 Accepted 28 February 2018 Published Online First 30 March 2018

\section{Linked}

- http://dx.doi.org/10.1136/ heartjnl-2018-313084

\section{Check for updates}

To cite: Engstrøm T, Nepper-Christensen L, Helqvist $S$, et al. Heart 2018:104:1593-1599.

\section{ABSTRACT}

Objectives Reperfusion immediately after reopening of the infarct-related artery in ST-segment elevation myocardial infarction (STEMI) may cause myocardial damage in addition to the ischaemic insult (reperfusion injury). The gap junction modulating peptide danegaptide has in animal models reduced this injury. We evaluated the effect of danegaptide on myocardial salvage in patients with STEMI.

Methods In addition to primary percutaneous coronary intervention in STEMI patients with thrombolysis in myocardial infarction flow $0-1$, single vessel disease and ischaemia time less than 6 hours, we tested, in a clinical proof-of-concept study, the therapeutic potential of danegaptide at two-dose levels. Primary outcome was myocardial salvage evaluated by cardiac MRI after 3 months.

Results From November 2013 to August 2015, a total of 585 patients were randomly enrolled in the trial. Imaging criteria were fulfilled for 79 (high dose), 80 (low dose) and 84 (placebo) patients eligible for the per-protocol analysis. Danegaptide did not affect the myocardial salvage index (danegaptide high $(63.9 \pm 14.9)$, danegaptide low $(65.6 \pm 15.6)$ and control $(66.7 \pm 11.7), P=0.40)$, final infarct size (danegaptide high $(19.6 \pm 11.4 \mathrm{~g})$, danegaptide low $(18.6 \pm 9.6 \mathrm{~g})$ and control (21.4 $\pm 15.0 \mathrm{~g}), \mathrm{P}=0.88)$ or left ventricular ejection fraction (danegaptide high $(53.9 \% \pm 9.5 \%)$, danegaptide low $(52.7 \% \pm 10.3 \%)$ and control $(52.1 \% \pm 10.9 \%)$, $\mathrm{P}=0.64$ ). There was no difference between groups with regard to clinical outcome.

Conclusions Administration of danegaptide to patients with STEMI did not improve myocardial salvage. Trial registration number NCT01977755; Pre-results.

\section{INTRODUCTION}

In patients with ST-segment elevation myocardial infarction (STEMI), the recommended therapy is primary percutaneous coronary intervention (PCI). ${ }^{1}$ Although acute restoration of myocardial blood flow is overall beneficial, it may in itself jeopardise the myocardium. This phenomenon, known as reperfusion injury, may account for up to $50 \%$ of myocardial infarct size, a major determinant of prognosis in patients with STEMI. ${ }^{2}$

A number of therapeutic interventions have been suggested to attenuate the extent of reperfusion injury. ${ }^{3}$ These are referred to as cardioprotective reperfusion strategies, and in experimental settings, several compounds have proven efficacious. ${ }^{3}$ However, although successful also in smaller sized surrogate trials, no compound has proven successful on clinical outcome. ${ }^{45}$ It has therefore been difficult to translate explorative results into specific treatment modalities, and well-documented cardioprotective strategies are still missing.

Connexin-43 is a major component of gap junctions that propagate signalling from cell to cell. Connexin-43 promotes ischaemic preconditioning and has also been shown to protect cardiomyocyte mitochondria. ${ }^{6}$ The dipeptide danegaptide increases gap junctional conductance by interaction with connexin- $43{ }^{7}$ It reduces myocardial infarct sizes in dogs and pigs ischaemia reperfusion models. ${ }^{8}$ Therefore, danegaptide could be a relevant candidate to address reperfusion injury in human. ${ }^{9}$

In addition to PCI in patients with STEMI, we tested, in a phase two clinical proof-of-concept study, the effect of danegaptide administered at two different dose levels relative to placebo on myocardial salvage.

\section{METHODS}

Between November 2013 and August 2015, 585 patients with STEMI were enrolled into a singlecentre, double-blinded, randomised, placebo-controlled trial to investigate the efficacy and safety of danegaptide at two different dose levels to patients undergoing PCI.

Patients underwent standard treatment provided to patients with STEMI undergoing PCI at Copenhagen University Hospital Rigshospitalet, Denmark, in addition to the experimental treatment.

The trial (EudraCT number 2013-002312-27) was conducted in accordance with Declaration of Helsinki and International Conference on Harmonisation Good Clinical Practice. The trial is registered at ClinicalTrials.gov, registration number NCT01977755. 
Zealand Pharma A/S, Denmark, funded the study and supplied the study drug.

\section{STUDY POPULATION AND TRIAL DESIGN}

Patients $\geq 18$ years presenting with symptoms within 12 hours of onset were eligible. STEMI was defined by one of following findings at ECG: (A) minimum $0.2 \mathrm{mV}$ ST-segment elevation in two or more leads (V1-V4), (B) new left bundle branch block with minimum of $0.1 \mathrm{mV}$ concordant ST segment elevation, (C) minimum $0.1 \mathrm{mV}$ ST-segment elevation in two or more limb leads (II, III and aVF, I, aVL), (D) minimum 0.1 mV ST-segment elevation in two or more leads (V4-V6). All patients provided informed consent prior to any trial-related procedures. Patients were excluded if in cardiogenic shock within 24 hours prior to randomisation, had been administered thrombolytics, had prior revascularisation in the same coronary artery as present culprit, needed a staged treatment of coronary artery disease or other procedures to treat heart disease, had known malignancy with a life expectancy of less than 2 years or if they had contraindication to cardiac MRI (CMR).

Patients were randomised before angiography to ensure early initiation of danegaptide infusion and thus obtain sufficient plasma concentration at the time of reperfusion. Sequentially numbered containers were used. All persons involved in the study were blinded to the allocated treatment. All patients fulfilling imaging criteria received CMR at day 2 and at a follow-up visit 90 days after the PCI.

Patients with thrombolysis in myocardial infarction (TIMI) flow grades 2-3 at admission had already experienced reperfusion and did not qualify for the imaging per-protocol (PP) population. Renal function should correspond to eGFR $>30 \mathrm{~mL} /$ min, and other lesions than the culprit should angiographically be $<70 \%$ in larger coronaries to avoid possible remote preconditioning from ischaemia behind these stenoses. Finally, in the imaging population, there should be less than 6 hours between onset of symptoms and successful PCI. The PP population was strictly prespecified and unchanged during the course of the study.

Follow-up visits took place after 2 weeks (telephone visit) after approximately 30 days (local hospital follow-up) and finally after 90 days at the index hospital (Rigshospitalet).

Randomisation continued to ensure that at least 195 patients would receive the day $2 \mathrm{CMR}$. The PP population for the primary analysis consisted of patients who had data available for calculation of the primary efficacy endpoint and no critical protocol violations. The trial was closed after all patients had completed day 90 visit.

Separate assessment of patients with TIMI flow 2-3, other stenosis $>70 \%$ and time of ischemia $>6$ hours from the primary efficacy analysis population is an enrichment strategy in line with recent recommendations on phase 2 trials in prevention of reperfusion injury. ${ }^{10}$

\section{STANDARD TREATMENT}

Patients were pretreated with aspirin $(300 \mathrm{mg}$ orally or $500 \mathrm{mg}$ intravenous), heparin (10.000 units intravenous) and either prasugrel (60 mg orally), ticagrelor $(180 \mathrm{mg}$ orally) or clopidogrel (600 mg orally). Bivalirudin was preferably administered before PCI if no contraindications were present. Treatment with glycoprotein IIb/IIIa inhibitors was allowed at the discretion of the operator. Additional heparin could be administered to maintain activated clotting time $($ ACT) $>250$ s. In all patients, drug-eluting stent implantation was recommended. All patients received 12 months of dual antiplatelet therapy.

\section{EXPERIMENTAL TREATMENT}

Patients were treated with danegaptide low dose (intravenous $2.5 \mathrm{mg}$ bolus injection followed by $7.5 \mathrm{mg}$ infused over 6 hours), danegaptide high dose (intravenous $7.5 \mathrm{mg}$ bolus injection followed by $22.5 \mathrm{mg}$ infused over 6 hours) or placebo. Bolus injections were administered at least $10 \mathrm{~min}$ prior to the PCI procedure. The infusion was administered over 6 hours, starting no later than $15 \mathrm{~min}$ after the bolus injection.

The selection of doses was based on extrapolation of the efficacious doses in a porcine model of ischaemia reperfusion injury ${ }^{8}$ and modelling using pharmacokinetic parameters obtained from two phase 1 trials with danegaptide (data not published). The duration of infusion was 6 hours to allow continuous exposure during the PCI procedure and the first hours after revascularisation to optimise chances of tissue salvage.

At the end of the procedure and after 7-12 hours, blood samples were drawn to analyse plasma danegaptide.

\section{ENDPOINTS}

\section{Primary endpoint}

The primary endpoint was mean myocardial salvage index (MSI) evaluated at day 90. MSI was defined as (area at risk - final infarct size)/area at risk. Area at risk (AAR) was assessed as oedema visualised by CMR using T2-weighted short tau inversion-recovery sequence at day 2. Final infarct size was assessed as hyperenhanced myocardial tissue using gadolinium-enhanced images at day 90. The CMR was performed as previously described. ${ }^{11}$ If the AAR by CMR was different across the three treatment arms, it could be claimed that danegaptide potentially influenced AAR. An alternative method for assessing the AAR endpoint was therefore based on the modified Alberta Provincial Project for Outcome Assessment in Coronary Heart Disease (APPROACH) score as derived from coronary angiography performed shortly before PCI. ${ }^{12}$ The assessment was performed blinded by two independent investigators. In case of discordant assessment, the investigators reached a consensus agreement.

\section{Secondary CMR endpoints}

Key secondary CMR endpoints included: absolute infarct size (day 2 and day 90), left ventricular ejection fraction (LVEF) (day 2 and day 90) and microvascular obstruction by CMR at day 2 .

\section{Non-imaging endpoints}

Non-imaging endpoints were measured on all patients and included arrhythmias, ST-segment resolution by ECG at $60 \mathrm{~min}$ after PCI and fraction of patients having $\geq 70 \%$ ST-segment resolution at $60 \mathrm{~min}$, area under the curve for cardiac biomarkers for creatine kinase-MB and Troponin $\mathrm{T}(\mathrm{TnT})$ calculated for the 48 hours period after PCI. Clinical endpoints comprised all-cause mortality, cardiac death, heart failure and reinfarction. Heart failure was assessed as new onset or worsening heart failure during index admission or readmission for heart failure during the 90-day follow-up.

\section{Safety endpoints}

Safety signals were monitored blinded by an independent Data Safety Monitoring Board.

A Clinical Events Committee was responsible for adjudication of major adverse clinical events (cardiac death, new or worsening heart failure during the initial hospitalisation and 
rehospitalisation due to heart failure) as well as selected safety-related events relevant for the indication (myocardial reinfarction, stent thrombosis and stroke).

\section{Sample size and statistical analysis}

Sample size was calculated from the assumption that the MSI in the placebo-treated patients would be 0.62 and that danegaptide would improve MSI by $15 \%$ giving to $0.71 .^{13}$ With a power of $80 \%$, type 1 error of $5 \%$, common SD of 0.16 , a minimum sample size of 51 patients per imaging group was required. It was assumed that $75 \%$ of the randomised patients with CMR scan at day 2 after PCI would complete day 90 CMR scan and be eligible for the primary analysis. This implied 70 patients per treatment arm, amounting a total of 210 patients with day 2 CMR scan. The 210 patients with day 2 CMR scan and the additional requirements of pre-PCI TIMI flow $0 / 1$ and $<70 \%$ stenosis in other vessels and less than 6 hours of ischaemia was thus the essential sample size. Approximately $35 \%$ of randomised patients were expected to fulfil these requirements, corresponding to 600 patients randomised.

The assumption that $75 \%$ of the patients would complete both the day 2 and day $90 \mathrm{CMR}$ was after monitoring the drop-out rate changed to at least $80 \%$. Thus, the target number of patients with day 2 CMR scan was reduced to 195 patients, which would still ensure at least 51 patients per treatment group for the primary analysis.

Statistical analyses (SAS software, V.9.4) were performed on two distinct analysis populations. The full analysis set comprised all intention-to-treat patients who received (1) at least one dose of trial drug and (2) had at least one valid postbaseline efficacy endpoint. The primary analysis of the primary efficacy parameter was based on the per-protocol (PP) population. The PP population for the primary analysis consisted of patients who had data available for calculation of the primary efficacy endpoint and no critical protocol violations.

The MSI as well as the APPROACH score and other imaging endpoints were analysed using an analysis of covariance model with treatment group, gender and TIMI 0-1 pre-PCI as independent factors and relative infarct size at baseline together with age as covariates. Final infarct size was analysed in a simple linear regression on AAR at baseline, with the regression depending on treatment group.

For the PP population, baseline characteristics were compared across the treatment arms using the Wilcoxon test in

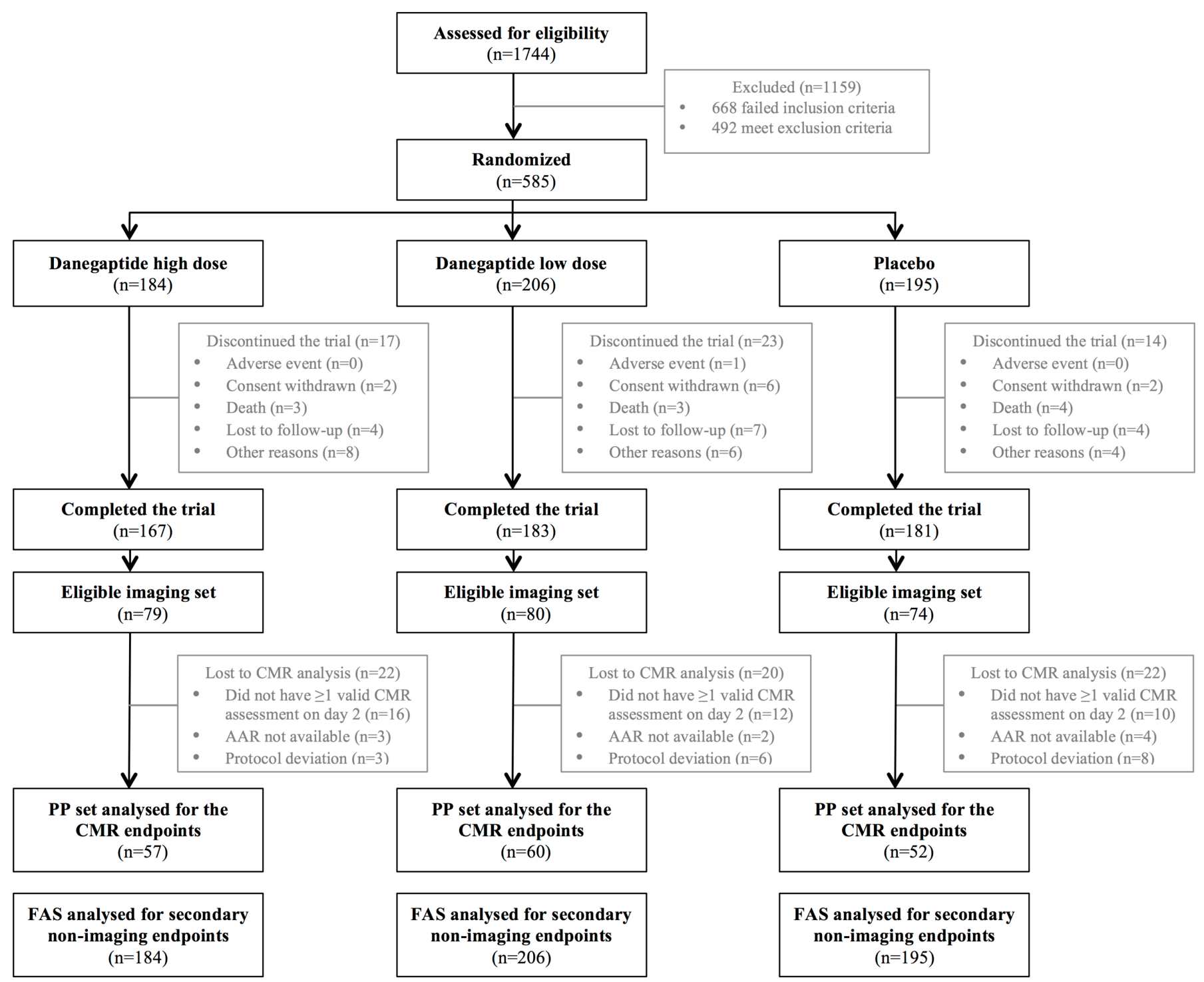

Figure 1 Consort flow chart. AAR, area at risk; CMR, cardiac MRI; FAS, full analysis set; PP, per protocol. 
the continuous and Fisher's exact test in the categorical case. Similar procedures were used to compare baseline characteristics between the PP and the non-PP groups. Overall occurrences of adverse events and deaths were compared using a Poisson assumption.

\section{RESULTS}

\section{Study population}

Between November 2013 and December 2015, 585 patients were randomised to high dose danegaptide $(n=184)$, low dose danegaptide $(n=206)$ or placebo $(n=195)$. Figure 1 shows the consort flow chart. All together 57 (high dose), 60 (low dose) and 52 (placebo) fulfilled the PP imaging criteria for analysis for the primary endpoint.
Baseline, angiographic and procedural characteristics are shown in table 1 . The randomisation groups from the PP set were well balanced except from more patients being smokers in the danegaptide high dose $\operatorname{arm}(\mathrm{P}=0.005)$. In the non-PP set, patients were older, had longer symptom to first medical contact, longer door to balloon, longer bolus drug administration (IMP) to first wire, longer time of ischaemia, more collateral flow, more thrombectomy and less stent implantation (table 1).

Plasma concentrations of danegaptide from all patients closely reflected the dose in the three treatment groups with the highest danegaptide concentration in the danegaptide high group (mean $451 \pm 369 \mathrm{ng} / \mathrm{mL}$ ) at the first time point, lower concentration in the danegaptide low group (mean $141 \pm 48.4 \mathrm{ng} / \mathrm{mL}$ ) and no plasma danegaptide in the placebo group (figure 2).

Table 1 Baseline clinical, angiographic and procedural characteristics

\begin{tabular}{|c|c|c|c|c|c|c|c|}
\hline & \multicolumn{3}{|c|}{ Full analysis set $(\mathrm{N}=585)$} & \multicolumn{3}{|c|}{ Per-protocol set $(\mathrm{N}=169)$} & \multirow[b]{2}{*}{$P$ values } \\
\hline & $\begin{array}{l}\text { Danegaptide high } \\
(\mathrm{n}=184)\end{array}$ & $\begin{array}{l}\text { Danegaptide low } \\
(\mathrm{n}=206)\end{array}$ & $\begin{array}{l}\text { Placebo } \\
(n=195)\end{array}$ & $\begin{array}{l}\text { Danegaptide } \\
\text { high } \\
(n=57)\end{array}$ & $\begin{array}{l}\text { Danegaptide } \\
\text { low } \\
(n=60)\end{array}$ & $\begin{array}{l}\text { Placebo } \\
(n=52)\end{array}$ & \\
\hline Age (years) & $60.5 \pm 11.6$ & $60.0 \pm 11.1$ & $61.0 \pm 10.9$ & $57.0 \pm 10.5$ & $57.3 \pm 9.1$ & $56.0 \pm 9.7$ & 0.776 \\
\hline $\mathrm{BMI}\left(\mathrm{kg} / \mathrm{m}^{2}\right)$ & $27.3 \pm 3.8$ & $26.9 \pm 4.1$ & $27.4 \pm 4.3$ & $27.7 \pm 4.6$ & $26.8 \pm 4.3$ & $27.6 \pm 4.2$ & 0.560 \\
\hline Male & $145(78.8)$ & $160(77.7)$ & $146(74.9)$ & $46(80.7)$ & $47(78.3)$ & $45(86.5)$ & 0.509 \\
\hline Current smokers & $83(45.1)$ & $87(42.2)$ & $80(41.0)$ & $34(59.6)$ & $20(33.3)$ & $17(32.7)$ & 0.005 \\
\hline Killip Class I & $178(96.7)$ & $198(96.6)$ & $192(98.5)$ & $56(98.2)$ & $60(100.0)$ & $52(100.0)$ & 0.645 \\
\hline Diabetes mellitus & $16(8.7)$ & $22(10.7)$ & $23(11.8)$ & $4(7.0)$ & $5(8.3)$ & $6(11.5)$ & 0.747 \\
\hline Family history of IHD & $70(38.0)$ & $82(39.8)$ & 79 (40.5) & $24(42.1)$ & $27(45.0)$ & $24(46.2)$ & 0.924 \\
\hline History of stroke & $5(2.7)$ & $7(3.4)$ & $12(6.2)$ & $3(5.3)$ & $0(0.0)$ & $3(5.8)$ & 0.142 \\
\hline Hypercholesterolaemia & $31(16.8)$ & $28(13.6)$ & $35(17.9)$ & $7(12.3)$ & $11(18.3)$ & $4(7.7)$ & 0.265 \\
\hline Hypertension & $70(38.0)$ & $61(29.6)$ & $79(40.5)$ & $24(42.1)$ & $13(21.7)$ & $15(28.8)$ & 0.054 \\
\hline $\begin{array}{l}\text { Symptoms to first medical contact time } \\
\text { (h) }\end{array}$ & $0.9(0.0-10.6)$ & $0.9(0.0-9.8)$ & $1.0(0.0-31.2)$ & $0.8(0.0-4.3)$ & $0.9(0.0-4.1)$ & $1.0(0.0-4.2)$ & 0.721 \\
\hline $\begin{array}{l}\text { First medical contact to hospital arrival } \\
\text { (h) }\end{array}$ & $1.1(0.2-4.3)$ & $1.1(0.0-22.3)$ & $1.2(0.1-4.0)$ & $1.0(0.2-4.3)$ & $1.0(0.4-2.2)$ & $1.0(0.3-4.0)$ & 0.747 \\
\hline Door-to-balloon time $(\mathrm{h})$ & $0.5(0.2-1.9)$ & $0.5(0.2-2.6)$ & $0.5(0.2-3.0)$ & $0.5(0.2-1.9)$ & $0.4(0.3-2.6)$ & $0.5(0.3-1.6)$ & 0.400 \\
\hline Bolus IMP to first wire $(\mathrm{h})$ & $0.3(0.1-1.3)$ & $0.3(0.1-1.2)$ & $0.3(0.2-0.9)$ & $0.3(0.2-0.8)$ & $0.3(0.2-0.6)$ & $0.3(0.2-0.8)$ & 0.135 \\
\hline Total ischaemic time $(\mathrm{h})$ & $2.6(1.2-12.7)$ & $2.6(0.7-10.0)$ & $2.7(1.2-32.7)$ & $2.4(1.2-5.8)$ & $2.4(1.3-5.9)$ & $2.8(1.2-5.9)$ & 0.626 \\
\hline Total ischaemic time $<2$ houra & $38(23.2)$ & $41(21.8)$ & $35(19.1)$ & $13(22.8)$ & $15(25.0)$ & $12(23.1)$ & 0.464 \\
\hline Total ischaemic time $2-<3$ hours & $62(37.8)$ & $74(39.4)$ & $70(38.3)$ & $28(49.1)$ & $23(38.3)$ & $16(30.8)$ & \\
\hline Total ischaemic time $3-<4$ hours & $23(14.0)$ & $32(17.0)$ & $32(17.5)$ & $7(12.3)$ & $13(21.7)$ & $13(25.0)$ & \\
\hline Total ischaemic time $4-<6$ hours & $29(17.7)$ & $27(14.4)$ & $32(17.5)$ & $9(15.8)$ & $9(15.0)$ & $11(21.2)$ & \\
\hline Total ischaemic time >6hours & $12(7.3)$ & $14(7.4)$ & $14(7.7)$ & $0(0.0)$ & $0(0.0)$ & $0(0.0)$ & \\
\hline Left anterior infarct & $76(41.3)$ & $80(38.8)$ & $83(42.6)$ & $26(45.6)$ & $26(43.3)$ & $28(53.8)$ & 0.820 \\
\hline Left circumflex infarct & $22(12.0)$ & $23(11.2)$ & 35 (17.9) & $5(8.8)$ & 7 (11.7) & $4(7.7)$ & \\
\hline Right coronary infarct & $68(37.0)$ & $86(41.7)$ & $70(35.9)$ & $26(45.6)$ & $27(45.0)$ & $20(38.5)$ & \\
\hline Collateral flow (Rentrop grade $2 / 3$ ) & $9(4.9)$ & $9(4.4)$ & $11(5.6)$ & $2(3.5)$ & $5(8.3)$ & $1(1.9)$ & 0.310 \\
\hline TIMI grade 3 after procedure & $156(95.7)$ & $183(96.8)$ & $179(97.8)$ & $56(98.2)$ & $60(100.0)$ & $50(96.2)$ & 0.204 \\
\hline Thrombectomy & $70(41.7)$ & $76(40.2)$ & $82(43.6)$ & $28(49.1)$ & $29(48.3)$ & $26(50.0)$ & 1.000 \\
\hline Stent implantation & $151(89.9)$ & $168(88.9)$ & $169(89.9)$ & $56(98.2)$ & $58(96.7)$ & $52(100.0)$ & 0.775 \\
\hline \multicolumn{8}{|l|}{ Medical therapy at discharge } \\
\hline ACE inhibitor & $66(36)$ & $76(37)$ & $72(37)$ & & & & \\
\hline Beta blocking agents & $178(97)$ & $193(94)$ & $195(100)$ & & & & \\
\hline Acetylsalicylic acid & $184(100)$ & $205(100)$ & $195(100)$ & & & & \\
\hline Clopidogrel & $21(11)$ & $20(10)$ & $26(13)$ & & & & \\
\hline Prasugrel & $53(29)$ & $76(37)$ & $68(35)$ & & & & \\
\hline Ticagrelor & $104(57)$ & $107(52)$ & $98(50)$ & & & & \\
\hline Statins & $176(96)$ & $196(95)$ & $190(97)$ & & & & \\
\hline
\end{tabular}

Data are presented as mean \pm SD, median (range) or $\mathrm{N}(\%)$, unless otherwise indicated.

${ }^{*} \mathrm{P}$ values for test of equality across treatment arms in the PP set are derived from the Wilcoxon test or Fisher's exact test.

BMI, body mass index; h, hours; IHD, ischaemic heart disease; IMP, investigational medicinal product; N, number of patients; TIMI, thrombolysis in myocardial infarction. 


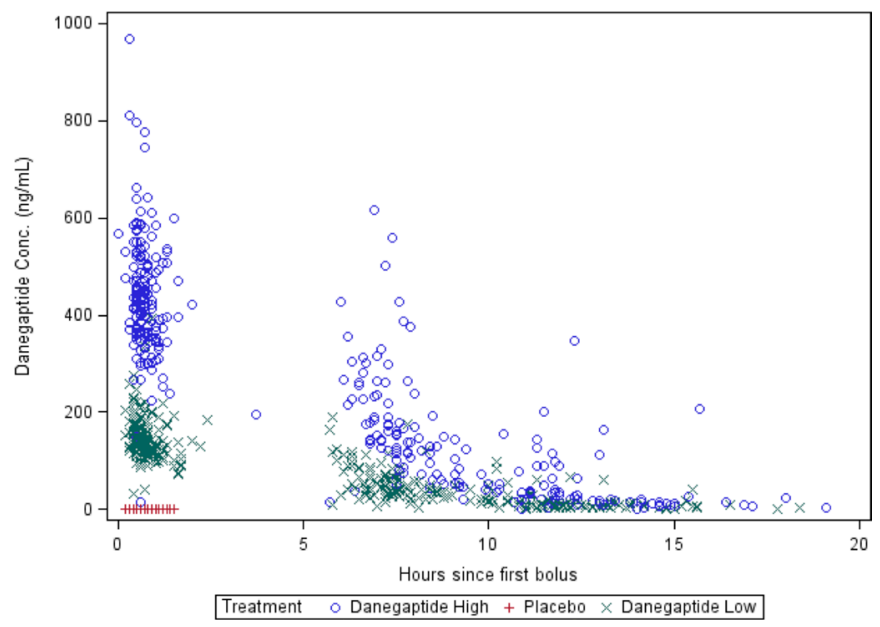

Figure 2 Danegaptide concentrations at end of $\mathrm{PCl}$ procedure and $7-12$ hours after $\mathrm{PCl}$ procedure. $\mathrm{PCl}$, percutaneous coronary intervention.

\section{Primary endpoint}

The result of the primary endpoint is shown in table 2. MSI was approximately 60\%-65\%, and no significant differences between allocation groups were found $(\mathrm{P}=0.40)$ or variant MSI $(\mathrm{P}=0.64)$. Due to one extreme outlier, the mean of the AAR as evaluated by CMR as well as by modified APPROACH score was numerically larger in the control group (table 2).

In a regression analysis of infarct size plotted against AAR, the lines for the three treatment groups were indifferent $(P>0.05$, figure 3). In all groups, the infarct size correlated with AAR (control: $\mathrm{r}^{2}=0.753, \mathrm{P}<0.0001$, danegaptide high: $\mathrm{r}^{2}=0.496$, $\mathrm{P}<0.0001$ and danegaptide low: $\left.\mathrm{r}^{2}=0.407, \mathrm{P}<0.0001\right)$.

\section{Secondary endpoints}

Secondary CMR endpoints did not reveal significant differences between assignment groups (table 2), nor did non-imaging secondary endpoints $\left(\mathrm{AUC}_{\mathrm{CKMB}, 48}\right.$ (danegaptide high $(3830 \pm 2749 \mu \mathrm{g} \times \mathrm{h} / \mathrm{L})$, danegaptide low $(3468 \pm 2499 \mu \mathrm{g} \times \mathrm{h} / \mathrm{L})$ and control $(3246 \pm 2621 \mu \mathrm{g} \times \mathrm{h} / \mathrm{L}), \quad \mathrm{P}=0.13) ; \quad \mathrm{AUC}_{\mathrm{TnT}, 48}$, (danegaptide high (167 568 $\pm 156757 \mathrm{ng} \times \mathrm{h} / \mathrm{L})$, danegaptide low $(175173 \pm 161646 \mathrm{ng} \times \mathrm{h} / \mathrm{L})$ and control

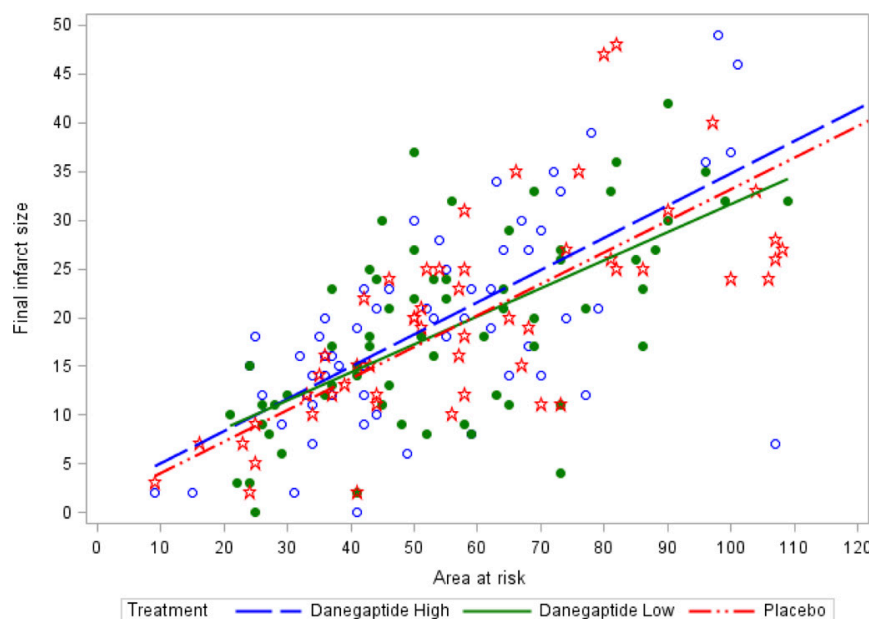

Figure 3 Final infarct size as a function of AAR. Infarct size correlated well with AAR for all treatment groups (control: $\mathrm{r}^{2}=0.753, \mathrm{P}<0.0001$, danegaptide high: $r 2=0.496, P<0.0001$, danegaptide low: $r 2=0.407$, $\mathrm{P}<0.0001)$. $A A R$, area at risk.

$(164000 \pm 170992 \mathrm{ng} \times \mathrm{h} / \mathrm{L}), \mathrm{P}=0.82)$; presence of $70 \%$ ST-segment resolution after $60 \mathrm{~min}$ (danegaptide high 89 patients (65.4\%), danegaptide low 104 patients (68.0\%) and control 93 patients $(61.6 \%), \mathrm{P}=0.51)$ ).

There was no difference between groups with regard to all-cause mortality $(1.6 \%, 1.5 \%, 2.1 \%, \mathrm{P}=0.90)$, cardiac death $(1.6 \%, 1.5 \%, 2.1 \%, \mathrm{P}=0.90)$, reinfarction $(0.5 \%, 1.0 \%, 1.0 \%$, $\mathrm{P}=0.66)$ after 90 days or development of heart failure $(7.1 \%$, $4.9 \%, 4.1 \%, \mathrm{P}=0.44)$.

\section{Safety endpoints}

Danegaptide was well tolerated. Few side effects were reported. All adverse events, serious adverse events or deaths were not different between groups (table 3).

\section{DISCUSSION}

The present study investigated the effect of two doses of danegaptide as adjuvant therapy to primary PCI in patients presenting with STEMI and TIMI flow $0-1$ within 6 hours of symptom debut. The trial was adequately sized for its purpose. The primary

Table 2 Outcomes evaluated with cardiac MRI

\begin{tabular}{|c|c|c|c|c|}
\hline & \multicolumn{3}{|l|}{ Full analysis set set $(n=169)$} & \multirow[b]{2}{*}{$P$ values } \\
\hline & Danegaptide high $(n=57)$ & Danegaptide low $(n=60)$ & Placebo $(n=52)$ & \\
\hline CMR AAR (\%LV) & $35.6 \pm 10.8$ & $37.4 \pm 11.4$ & $39.2 \pm 13.8$ & 0.333 \\
\hline CMR AAR (g) & $54.7 \pm 24.3$ & $55.4 \pm 21.5$ & $64.4 \pm 40.0$ & 0.460 \\
\hline Acute infarct size (\%LV) & $21.7 \pm 10.6$ & $21.2 \pm 9.7$ & $24.2 \pm 13.0$ & 0.575 \\
\hline Acute infarct size (g) & $33.5 \pm 20.4$ & $33.5 \pm 20.4$ & $33.5 \pm 20.4$ & 0.416 \\
\hline Final infarct size (\%LV) & $14.0 \pm 7.1$ & $13.7 \pm 6.7$ & $15.4 \pm 7.7$ & 0.950 \\
\hline Final infarct size (g) & $19.6 \pm 11.4$ & $18.6 \pm 9.6$ & $21.4 \pm 15.0$ & 0.880 \\
\hline Presence of MVO & $40(72.7)$ & $39(67.2)$ & $37(72.5)$ & 0.638 \\
\hline LVEF 90 days (\%) & $53.9 \pm 9.5$ & $52.7 \pm 10.3$ & $52.1 \pm 10.9$ & 0.638 \\
\hline MSI & $63.9 \pm 14.9$ & $65.6 \pm 15.6$ & $66.7 \pm 11.7$ & 0.395 \\
\hline Modified APPROACH score & $26.8 \pm 11.0$ & $27.7 \pm 11.4$ & $30.4 \pm 11.4$ & 0.147 \\
\hline Variant MSI & $42.2 \pm 33.9$ & $45.4 \pm 28.5$ & $45.7 \pm 33.6$ & 0.637 \\
\hline
\end{tabular}

Data are presented as mean \pm SD or $n(\%)$.

MSI calculated as: (CMR AAR (g) - final infart size (g))/CMR AAR (g).

Variant MSI calculated as: (modified APPROACH (\%) - final infarct size (\%))/modifiedAPPROACH (\%).

$P$ value derived from the Kruskal-Wallis non-parametric test excluding one extreme outlier.

AAR, area at risk; CMR, cardiac MRI; LV, left ventricle; LVEF, left ventricular ejection fraction; MSI, myocardial salvage index; MVo, Micro Vascular Obstruction 
Table 3 Summary of adverse events (AEs)

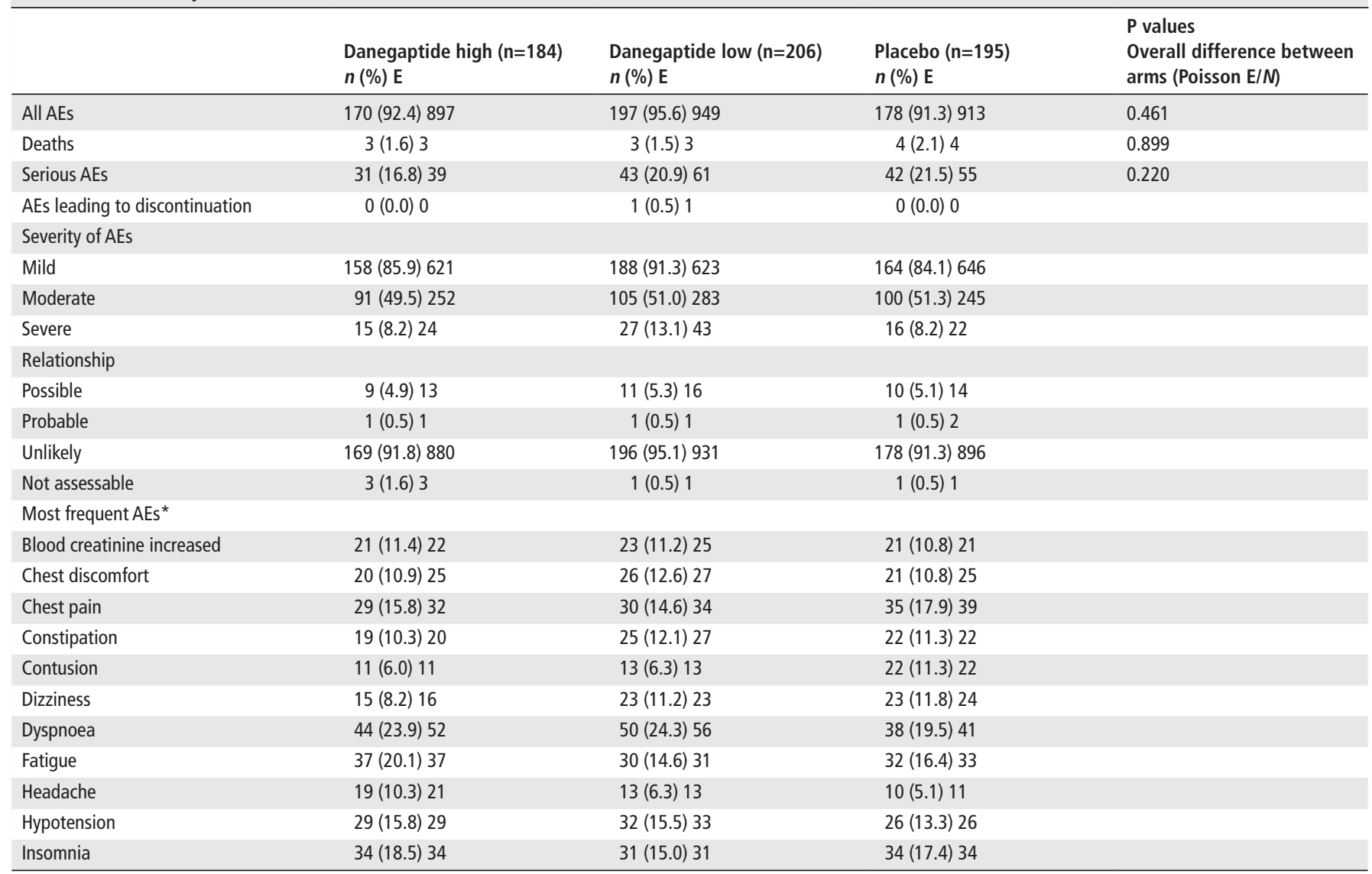

The DSMB met to review data safety packages non-blinded when day 30 data were available for 30, 200 and 400 patients.

${ }^{*} A E s$ included in the table are $A E s$ reported by $\geq 10 \%$ of patients in any treatment group.

DSMB, Data Safety Monitoring Board; $E$, number of AEs; $n$, number of patients with $A E ; N$, number of patients in safety analysis set; \%, percentage of patients with AE.

endpoint, MSI by CMR, did not differ between treatment groups, and therefore, in this clinical proof-of-concept trial, we were not able to confirm results from promising preclinical experiments. ${ }^{8}$ In STEMI, reperfusion may in itself jeopardise the myocardium, ${ }^{14}$ and therefore, a relevant cardioprotective strategy should reduce cardiomyocyte damage and increase salvage. Since left ventricular function is pivotally dependent on vital myocardium, markers of the integrity of the left ventricle are important measures. However, in addition to the results of the primary endpoint LVEF, microvascular obstruction and ST-segment resolution all remained indifferent between the allocated groups.

Previous pharmacological interventions have in small-sized proof-of-concept studies been shown to reduce reperfusion injury and improve myocardial salvage. These include exenatide, ${ }^{13}$ atrial natriuretic peptide, ${ }^{7}$ cyclosporine $\mathrm{A},{ }^{4}$ metoprolol ${ }^{15}$ and adenosin. ${ }^{16}$ Connexin- 43 , the predominant connexin isoform myocytes, is found in three different locations: (1) as the constituent protein of gap junctions, which are essential for metabolic and electrochemical coupling between cardiomyocytes ${ }^{9}$; (2) non-junctional connexin-43 haemichannels are involved in volume regulation and contribute to the development of oedema during ischaemia/reperfusion ${ }^{17}$; and (3) connexin-43 has been identified in cardiomyocyte mitochondria. Preclinical studies indicate that opening of the mitochondrial permeability transition pore in the inner mitochondrial membrane plays a major role in reperfusion injury. ${ }^{18}$ Based on these mechanisms, connexin-43-modulating peptides like danegaptide should be potential candidates for cardioprotection in human.

However, there are several explanations for the neutral finding in the present study. Treatment dose regimen was based on extrapolation of the efficacious doses in animal models $^{8}$ and human exposure from two phase 1 studies (data not shown) of danegaptide administered intravenously as a 24-hour infusion to healthy subjects. These investigations were mainly performed to evaluate side effects. In addition, reperfusion injury is established immediately and within minutes after reopening of the coronary artery ${ }^{19}$ and therefore any protecting compound should ideally be present in the target area (myocardium at risk) at the time of reperfusion. In the absence of sufficient collaterals (only $5 \%$ of patients had Rentrop 2-3 in the present study), and in the absence of antegrade flow (TIMI flow $0-1$ by definition), arrival of danegaptide may succeed the reperfusion damage and consequently act to late.

A number of experimental studies have shown cardioprotection from different compounds and techniques. ${ }^{3}$ However, no treatments have been implemented within the particular aspect of STEMI handling. This may be considered enigmatic per se, but it has to be remembered that differences exist between animal models and clinical settings. First, in contrast to human, animals are naive with regard to ischaemia, medication, comorbidity and risk factors. Second, in animal studies, AAR is large since these models use proximal or mid LAD occlusion to establish ischaemia, whereas in the present study, included arteries could be either LAD or other territories. Patients with small myocardium at risk may not benefit from a strategy that addresses reperfusion injury. Finally, events rates are decreasing in a modern STEMI era due to short transportation times, effective antiplatelet therapy and state of the art 
PCI. In general, patients treated with primary angioplasty have well preserved LVEF subsequently. ${ }^{20}$ Thus, any incremental effect of a new treatment may be difficult to obtain.

\section{Limitations}

CMR in acute setting of STEMI may be cumbersome, since the sickest patients may defer acceptance. This introduces a risk of selection bias since patients at higher risk probably are more likely not to accept or complete CMR. The concentration of danegaptide may not have reached a therapeutic level, and thus administration of the drug already in the ambulance could have been favourable. However, since circulating levels matched expectations, this seems unlikely. AAR by T2-weighted imaging may vary the first 7 days after a STEMI and be reduced in 24 hours $^{21}$ with a risk of underestimation of AAR. However, other studies find it unchanged within the first 7 days. ${ }^{22}$ Moreover, the size of AAR measured in the present study is in the same range as reported in other papers. We acknowledge the limitation of T2-weighted imaging, and for the same reason we also used angiography (modified APPROACH score). Thus, we feel quite convinced that any potential effect of danegaptide is not blunted by the use of T2-weighted imaging. Difference in the number of patients randomised to each group (184 vs 206 vs 195 ) is greater than $10 \%$. Randomisation procedures were prespecified and unchanged during the course of the study. The difference must to the best of our interpretation be due to chance.

\section{CONCLUSION}

Danegaptide did not improve myocardial salvage in patients with STEMI treated with primary PCI.

\section{Key messages}

\section{What is already known on this subject?}

- Reperfusion injury is still a matter of importance since patients who suffer this outcome from primary percutaneous coronary intervention end up with large final infarct sizes. In addition, despite promising animal studies, no single agent has been approved for this indication.

\section{What might this study add?}

- The study could not confirm that the gap junction modulating peptide danegaptide reduces reperfusion injury in human ST-segment elevation myocardial infarction (STEMI).

\section{How might this impact on clinical practice?}

- As reperfusion injury is a complex pathophysiological incidence in STEMI, with a poor prognosis, it cannot be excluded that addressing other targets pharmaceutically could be beneficial.

\section{Acknowledgements We would like to thank the co-investigators and staff at Rigshospitalet.}

Contributors Planning: TE, LK, NV, KAA, JL, LN-C, AS, SF and UM. Conduct and reporting: all authors. Overall responsible: TE.

Funding Zealand Pharma A/S, Denmark funded the study and supplied the study drug.

Competing interests TE reports personal fees from Bayer, personal fees from St. Jude Medical, personal fees from Boston Scientific, personal fees from Medtronic, outside the submitted work and consultant fee and research grant from Zealand. JFL reports grants from St. Jude Medical/Abbott, personal fees from Biosensors, grants from Boston Scientific, grants from Biotronik, outside the submitted work. LK reports personal fees from Novartis as speaker, outside the submitted work. JL reports personal fees from St. Jude Medical, outside the submitted work.

\section{Patient consent Not required.}

Ethics approval The trial was approved by the Independent Ethics Committee and the Danish Health and Medicines Agency (DHMA; Jour. No.: 2013102384).

Provenance and peer review Not commissioned; externally peer reviewed.

(c) Article author(s) (or their employer(s) unless otherwise stated in the text of the article) 2018. All rights reserved. No commercial use is permitted unless otherwise expressly granted.

\section{REFERENCES}

1 Windecker S, Kolh P, Alfonso F, et al. 2014 ESC/EACTS Guidelines on myocardial revascularization: The Task Force on Myocardial Revascularization of the European Society of Cardiology (ESC) and the European Association for Cardio-Thoracic Surgery (EACTS)Developed with the special contribution of the European Association of Percutaneous Cardiovascular Interventions (EAPCI). Eur Heart J 2014;35:2541-619.

2 Yellon DM, Hausenloy DJ. Myocardial reperfusion injury. N Engl I Med Overseas Ed 2007:357:1121-35.

3 Lønborg JT. Targeting reperfusion injury in the era of primary percutaneous coronary intervention: hope or hype? Heart 2015;101:1612-8.

4 Cung TT, Morel O, Cayla G, et al. Cyclosporine before $\mathrm{PCl}$ in patients with acute myocardial infarction. N Engl J Med 2015;373:1021-31.

5 Ross AM, Gibbons RJ, Stone GW, et al. A randomized, double-blinded, placebocontrolled multicenter trial of adenosine as an adjunct to reperfusion in the treatment of acute myocardial infarction (AMISTAD-II). J Am Coll Cardiol 2005;45:1775-80.

6 Schwanke U, Konietzka I, Duschin A, et al. No ischemic preconditioning in heterozygous connexin43-deficient mice. Am J Physiol Heart Circ Physiol 2002;283:H 740-H1742.

7 Dhein S, Hagen A, Jozwiak J, et al. Improving cardiac gap junction communication as a new antiarrhythmic mechanism: the action of antiarrhythmic peptides. Naunyn Schmiedebergs Arch Pharmacol 2010;381:221-34.

8 Skyschally A, Walter B, Schultz Hansen R, et al. The antiarrhythmic dipeptide ZP1609 (danegaptide) when given at reperfusion reduces myocardial infarct size in pigs. Naunyn Schmiedebergs Arch Pharmacol 2013;386:383-91.

9 Pecoraro M, Sorrentino R, Franceschelli S, et al. Doxorubicin-mediated cardiotoxicity: role of mitochondrial connexin 43. Cardiovasc Toxicol 2015;15:366-76.

10 Ovize M, Thibault H, Przyklenk K. Myocardial conditioning: opportunities for clinical translation. Circ Res 2013;113:439-50.

11 Lønborg J, Vejlstrup N, Kelbæk H, et al. Final infarct size measured by cardiovascular magnetic resonance in patients with ST elevation myocardial infarction predicts long-term clinical outcome: an observational study. Eur Heart J Cardiovasc Imaging 2013:14:387-95

12 Ortiz-Pérez JT, Meyers SN, Lee DC, et al. Angiographic estimates of myocardium at risk during acute myocardial infarction: validation study using cardiac magnetic resonance imaging. Eur Heart J 2007;28:1750-8

13 Lonborg J, Vejlstrup N, Kelbæk H, et al. Exenatide reduces reperfusion injury in patients with ST-segment elevation myocardial infarction. Eur Heart J 2012:33:1491-9.

14 Ibáñez B, Heusch G, Ovize M, et al. Evolving therapies for myocardial ischemia/ reperfusion injury. J Am Coll Cardiol 2015;65:1454-71.

15 Ibanez B, Macaya C, Sánchez-Brunete V, et al. Effect of early metoprolol on infarct size in ST-segment-elevation myocardial infarction patients undergoing primary percutaneous coronary intervention: the Effect of Metoprolol in Cardioprotection During an Acute Myocardial Infarction (METOCARD-CNIC) trial. Circulation 2013;128:1495-503

16 Mahaffey KW, Puma JA, Barbagelata NA, et al. Adenosine as an adjunct to thrombolytic therapy for acute myocardial infarction: results of a multicenter, randomized, placebo-controlled trial: the Acute Myocardial Infarction STudy of ADenosine (AMISTAD) trial. J Am Coll Cardiol 1999;34:1711-20.

17 Garcia-Dorado D, Andres-Villarreal M, Ruiz-Meana M, et al. Myocardial edema: a translational view. J Mol Cell Cardiol 2012;52:931-9.

18 Crompton M, Costi A. A heart mitochondrial Ca2(+)-dependent pore of possible relevance to re-perfusion-induced injury. Evidence that ADP facilitates pore interconversion between the closed and open states. Biochem J 1990;266:33-9.

19 Bell RM, Bøtker HE, Carr RD, et al. 9th Hatter biannual meeting: position document on ischaemia/reperfusion injury, conditioning and the ten commandments of cardioprotection. Basic Res Cardiol 2016:111:41.

20 Kelbæk H, Høfsten DE, Køber L, et al. Deferred versus conventional stent implantation in patients with ST-segment elevation myocardial infarction (DANAMI 3-DEFER): an open-label, randomised controlled trial. Lancet 2016;387:2199-206.

21 Fernández-Jiménez R, Barreiro-Pérez M, Martin-García A, et al. Dynamic edematous response of the human heart to myocardial infarction: implications for assessing myocardial area at risk and salvage. Circulation 2017:136:1288-300.

22 Dall'Armellina E, Karia N, Lindsay AC, et al. Dynamic changes of edema and late gadolinium enhancement after acute myocardial infarction and their relationship to functional recovery and salvage index. Circ Cardiovasc Imaging 2011;4:228-36. 